\title{
Bronchiolitis Obliterans After Allogeneic Hematopoietic Stem Cell Transplantation
}

\author{
Kirsten M. Williams, MD, \\ Experimental Transplantation and Immunology Branch, National Cancer Institute, National \\ Institutes of Health, Bethesda, Maryland \\ Jason W. Chien, MD, MS, \\ Clinical Research Division, Fred Hutchinson Cancer Research Center and Pulmonary and Critical \\ Care, University of Washington, Seattle \\ Mark T. Gladwin, MD, \\ Division of Pulmonary, Allergy, and Critical Care Medicine, Hemostasis and Vascular Biology \\ Research Institute, University of Pittsburgh Medical Center, Pittsburgh, Pennsylvania \\ Steven Z. Pavletic, MD \\ Experimental Transplantation and Immunology Branch, National Cancer Institute, National \\ Institutes of Health, Bethesda, Maryland
}

\begin{abstract}
With improvements in supportive care, both long-term survival following allogeneic hematopoietic stem cell transplantations (HSCTs) and the indications for this procedure have increased. As a result, the number of patients living with long-term toxic effects due to HSCT has increased. A once rare condition of the donor immune cells attacking healthy host tissues, termed chronic graftvs-host disease, has become a more common phenomenon. When chronic graftvs-host disease affects the lung tissue, bronchiolitis obliterans syndrome ensues. Recent data suggest that bronchiolitis obliterans syndrome may affect up to $6 \%$ of HSCT recipients and dramatically alters
\end{abstract}

Corresponding Author: Kirsten M. Williams, MD, Experimental Transplantation and Immunology Branch, National Cancer Institute, Bldg 10 CRC, Room 3-3288, 10 Center Dr, Bethesda, MD 20892 (williaki@ mail.nih.gov).

Author Contributions: Drs Williams, Chien, and Pavletic presented the grand rounds. Drs Williams, Chien, Gladwin, and Pavletic wrote the manuscript and compiled the literature review. Dr Williams takes responsibility for the integrity of the data of the accuracy of the data analysis.

Study concept and design: Williams, Pavletic.

Acquisition of data: Williams, Pavletic.

Analysis and interpretation of data: Williams, Chien, Gladwin, Pavletic.

Drafting of the manuscript: Williams, Chien, Pavletic.

Critical revision of the manuscript for important intellectual content: Williams, Chien, Gladwin, Pavletic.

Administrative, technical or material support: Williams.

Study supervision: Chien, Gladwin, Pavletic.

Additional Contributions: We are grateful to the patient for providing permission to publish this information about her case. We thank Adeline Louie, MD (Diagnostic Radiology Branch, National Institutes of Health), for her interpretation of radiographic findings of the case patient and review of the manuscript; David Kleiner, MD (Pathology Branch, National Institutes of Health), for his interpretation of the biopsy specimen of the case patient and review of the manuscript; and Ronald Gress, MD (Experimental Transplantation and Immunology Branch, National Institutes of Health), for critical review of the manuscript. None of these persons was compensated for his or her contribution.

Financial Disclosures: None reported.

Publisher's Disclaimer: Disclaimer: The opinions expressed here are those of the authors and do not represent the official position of the National Institutes of Health or the US government. 
survival, with overall survival of only $13 \%$ at 5 years. These statistics have not improved since the first presentation of this disease over 20 years ago. Challenges to the progress of medical management of bronchiolitis obliterans syndrome include difficulties and delays in diagnosis and a paucity of data on pathogenesis to direct new therapies. This article critically evaluates the current diagnostic criteria for bronchiolitis obliterans syndrome and reviews the epidemiology, pathogenesis, and available treatments. Improvements in survival will likely require early disease recognition, allowing for therapeutic modulation of disease prior to the development of irreversible airway obliteration.

\section{CASE PRESENTATION}

A teenage female patient with chronic graft-vs-host disease presented for evaluation with a chief concern of shortness of breath 3 years following hematopoietic stem cell transplantation (HSCT). After achieving first complete remission for acute myeloid leukemia, she underwent a sibling donor, peripheral blood stem cell transplantation with reduced-intensity conditioning that included busulfan 3 years prior. Notably, her donor was cytomegalovirus seropositive and mismatched by serological typing at $1 H L A$ locus. Her early course after transplantation was complicated by acute graftvs-host disease of the skin.

Ten months after transplantation, she developed shortness of breath with wheezing and diarrhea. Subsequent workup revealed nonspecific ground-glass opacities on chest computed tomography (CT) scan and evidence of new airflow obstruction with air trapping on pulmonary function testing based on forced expiratory volume in the first second of expiration (FEV1) of $2.02 \mathrm{~L}$ ( $50 \%$ of predicted normal), a ratio of $\mathrm{FEV}_{1}$ to forced vital capacity of 0.64 , and residual volume of $1.52 \mathrm{~L}$ (157\% of predicted normal).

Bronchoalveolar lavage was nondiagnostic. Biopsies of the gastrointestinal tract demonstrated chronic inflammation with apoptotic bodies, crypt abscesses, and crypt loss, which are consistent with chronic graft-vs-host disease. Biopsy of the lungs revealed changes consistent with obliterative bronchiolitis.

Cultures from the lung biopsy were positive for Mycobacterium avium complex. After treatment with immunosuppression therapy (high-dose steroids, mycophenolate mofetil, and etanercept) and antimicrobial drugs, the gastrointestinal tract symptoms improved and the pulmonary function test parameters stabilized $\left(\mathrm{FEV}_{1}\right.$ ranged from $1.93 \mathrm{~L}$ at 426 days to 2.31 L at 520 days; FIGURE 1), even during withdrawal of immunosuppressive therapy. Approximately 1 month after cessation of immunosuppressive therapy and 17 months after transplantation, the patient developed increased shortness of breath and orthopnea, accompanied by evidence of worsening obstruction $\left(\mathrm{FEV}_{1}\right.$ decreased to $\left.1.68 \mathrm{~L}\right)$ on pulmonary function tests and there was increasing air trapping (residual volume $>220 \%$ ). Persistent decreased pulmonary function and worsening ground-glass densities on chest CT scan prompted a second open lung biopsy, which again revealed obliterative bronchiolitis. Further immunosuppressive therapy was instituted (with mycophenolate mofetil and highdose prednisone). She presented 1 month later to the Experimental Transplantation and Immunology Branch of the National Cancer Institute, National Institutes of Health (NIH). 
At this time, physical examination was notable for cushingoid appearance in this young woman with good air exchange bilaterally and expiratory wheeze on forced expiration. Pulmonary function tests revealed $\mathrm{FEV}_{1}$ of $1.74 \mathrm{~L}$ ( $50 \%$ of predicted normal), ratio of $\mathrm{FEV}_{1}$ to forced vital capacity of 0.4 , and residual volume of $2.08 \mathrm{~L}$ ( $206 \%$ of predicted normal). Chest CT revealed ground-glass opacities on inspiration and subtle air trapping on expiration. There was clinical evidence for associated chronic graft-vs-host disease of the gastrointestinal tract and liver. Oxygenation was stable during the 2- and 6-minute walk tests.

\section{Chronic Graft-vs-Host Disease}

Chronic graft-vs-host disease is a significant complication of allogeneic HSCT, ${ }^{1}$ affecting $30 \%$ to $70 \%$ of transplant recipients, ${ }^{2}$ Chronic graft-vshost disease is a multisystem alloimmune and autoimmune disorder, consisting of immunosuppression, immune dysregulation, decreased organ function, and impaired survival. Although most cases of chronic graft-vshost disease resolve, $15 \%$ of patients experience significant disease for longer than 5 years. ${ }^{3}$ Severe chronic graft-vshost disease confers a 5 -year survival of only $15 \%{ }^{4}$

The progress of treatment approaches for chronic graft-vs-host disease has been hindered by imprecise diagnosis and staging, lack of standardized measures of response, and paucity of information about disease pathogenesis. To approach these challenges, a NIH consensus project developed diagnostic staging and response criteria for chronic graft-vs-host disease and recommended guidelines for trial design. One of the most challenging manifestations of chronic graft-vs-host disease is chronic graft-vs-host disease of the lung, termed bronchiolitis obliterans syndrome, a rare and difficult-to-diagnose disease associated with high mortality.

\section{Bronchiolitis Obliterans Syndrome}

Bronchiolitis obliterans syndrome is a progressive, insidious lung disease occurring in a subset of patients after lung transplantation and allogeneic HSCT. ${ }^{8-11}$ Bronchiolitis obliterans syndrome results in progressive circumferential fibrosis and ultimate cicatrization of the small terminal airways, manifesting as new fixed airflow obstruction.

Allorecognition of lung antigens is the suspected etiology of bronchiolitis obliterans syndrome because lung transplantation and HSCT both involve alloimmunity-host (hematopoietic cells)-vs-graft (lung) disease for lung transplantation and graft (hematopoietic cells)-vs-host (lung) disease for HSCT. Additionally, when bronchiolitis obliterans syndrome occurs after HSCT, it is typically accompanied by alloimmune manifestations in other organs (eg, liver, eyes, or skin).

\section{Clinical Manifestations, Evaluations, and Diagnosis of Bronchiolitis Obliterans Syndrome}

Patients lack respiratory symptoms during mild stages of bronchiolitis obliterans syndrome, resulting in rare detection in the earliest stages of disease. Most patients present when the degree of airflow obstruction is severe, causing significant dyspnea on exertion, decreased exercise tolerance, and a persistent nonproductive cough. ${ }^{12}$ Physical examination is rarely 
helpful, but may reveal hyperinflation, diffuse crackles, or wheeze. ${ }^{12}$ Because these symptoms are nonspecific, other clinical processes, such as respiratory tract infections, should be considered.

In particular, bronchiolitis obliterans syndrome must be differentiated from cryptogenicorganizing pneumonia, also known as bronchiolitis obliterans—organizing pneumonia. While bronchiolitis obliterans is an obstructive process targeted at terminal bronchioles and rarely associated with infiltrates, cryptogenic-organizing pneumonia is generally a restrictive process targeted at alveoli and is almost always associated with alveolar infiltrates.

Clinical evaluation should include pulmonary function tests, inspiratory and expiratory highresolution chest $\mathrm{CT}$, and comprehensive infectious disease evaluation (including bronchoalveolar lavage with stains and cultures for viral, bacterial, fungal, and mycobacterial pathogens; blood cultures; cytomegalovirus polymerase chain reaction; and nasopharyngeal wash for respiratory viruses), and a thorough chronic graft-vs-host disease evaluation. Finally, echocardiography should be used to assess pulmonary artery pressure and a 6-minute walk evaluation for oxygenation status should be considered in the workup.

\section{Epidemiology and Clinical Significance}

Bronchiolitis obliterans syndrome is currently thought to be a rare complication of HSCT, affecting approximately $2 \%$ to $3 \%$ of all HSCT recipients, and $6 \%$ of patients with chronic graft-vs-host disease ${ }^{9,13-15}$ However, this incidence is likely an underestimate because these data largely come from a retrospective review of registry patients who received matchedsibling HSCTs. If unrelated donors were included, the incidence likely would be higher (unrelated donors confer a higher risk for chronic graft-vs-host disease, a risk factor for bronchiolitis obliterans syndrome). Furthermore, the incidence is also likely underreported due to the challenges in clinical diagnosis.

Early recognition of bronchiolitis obliterans syndrome is important because the severe form of the syndrome is rarely reversible and it causes significant morbidity and mortality. Eighty percent of cases occur within 18 months after transplantation. ${ }^{13}$ The 2-year overall survival rate has remained unchanged for 20 years (44\% in 1987 vs $45 \%$ in 2003) with a 5-year survival rate of only $13 \% .{ }^{9,16,17}$ This lack of progress highlights the need for investigations into disease pathogenesis and therapeutic trials.

\section{Pathogenesis}

Little is known regarding the pathogenesis of bronchiolitis obliterans syndrome after HSCT. A large retrospective HSCT registry study has associated the following risk factors with bronchiolitis obliterans syndrome: busulfanbased regimens, 14 months or longer duration from leukemia diagnosis to HSCT, peripheral blood stem cell source, female donor to male recipient, grades II to IV acute graft-vs-host disease, and previous interstitial pneumonitis. ${ }^{13}$ A study evaluating new airflow obstruction found increasing age, presence of airflow obstruction prior to the HSCT, acute and chronic graft-vshost disease, and history of viral respiratory tract infection also conferred an increased risk. ${ }^{18}$ Taken together, these studies suggest that prior respiratory insult (eg, chemotherapy, pneumonitis) or extensive 
inflammation during the peri-transplant time frame (due to T cells, acute graft-vs-host disease) may increase the risk for subsequent bronchiolitis obliterans syndrome.

Clinically, there is additional evidence that bronchiolitis obliterans syndrome is due to alloimmunity. New airflow obstruction generally develops during or after recent immunosuppression withdrawal, implicating an alloimmune reaction. Furthermore, the presence of neutrophils, plasma cells, and lymphocytes at the site of bronchiolar inflammation on lung biopsies suggests that donor immune cells play a role in lung destruction. ${ }^{19}$ Consistent with this interpretation that alloimmunity is critical to bronchiolitis obliterans syndrome genesis is the finding that airflow obstruction rarely occurs in the absence of chronic graft-vshost disease. ${ }^{18}$

Because bronchiolitis obliterans syndrome after lung transplantation is identical to bronchiolitis obliterans syndrome after HSCT from a clinical, pathological, immunologic, and physiological perspective, ${ }^{20,21}$ lung transplant data provide insight into the pathogenesis of bronchiolitis obliterans syndrome after HSCT. Alloimmune reactions have been substantiated in patients with bronchiolitis obliterans syndrome after lung transplantation. A HLA mismatch confers an increased risk of bronchiolitis obliterans syndrome, likely due to alloreaction to lung antigens. ${ }^{22}$

Lung transplant data also suggest that neutrophils and T lymphocytes mediate development of bronchiolitis obliterans syndrome. Neutrophilia in the bronchial fluid has been correlated with the development of bronchiolitis obliterans syndrome following lung transplantation. ${ }^{25}$ Improvements in $\mathrm{FEV}_{1}$ have been linked to the decrease in neutrophilia. ${ }^{24}$ Data to implicate $\mathrm{T}$ lymphocytes in the genesis of bronchiolitis obliterans syndrome after lung transplantation has involved CD4 effector T cells, CD8 effector T cells, and T-regulatory populations. After lung transplantation, an oligoclonal CD4 T-cell repertoire in peripheral blood is evident in patients with bronchiolitis obliterans syndrome. ${ }^{25}$ This expansion of a few CD4 T-cell clones is consistent with activation against lung selfantigens in the presence of major histocompatibility complex class II. Similarly, an aberrant interaction between CD8 T-cell and HLA class I has been suggested by detection of anti-HLA class I antibodies in patients preceding bronchiolitis obliterans syndrome after lung transplantation. ${ }^{26}$

Recently, a murine model demonstrated that these antibodies could generate bronchiolitis obliterans syndrome findings in lung epithelia and linked this to the generation of IL-17 in the lung. ${ }^{27}$ In clinical studies, increased production of IL-17 in bronchial fluid correlated with bronchiolitis obliterans syndrome after lung transplantation. ${ }^{28,29}$ Furthermore, data suggest that IL-17 generation is dependent on alloimmunity against the antigen collagen type $\mathrm{V}$, a collagen not typically exposed to immune cells. ${ }^{29}$ The production of IL-17 also has been linked to the production of IL-8, a cytokine contributing to neutrophilia observed in bronchiolitis obliterans syndrome after lung transplantation. ${ }^{30}$ Finally, peripheral Tregulatory populations have been implicated in this process; low levels have correlated with progressive disease. ${ }^{31-33}$

Collectively, these data suggest that a mechanism of bronchiolitis obliterans syndrome after transplantation could involve epithelial damage with collagen $\mathrm{V}$ antigen exposure, elevated 
levels of anti-HLA class I antibodies and IL-17 with coincident elevation in IL-8, leading to neutrophilia and the development of activated CD4 and CD8 Teffector cells, with ongoing lung damage aided by low levels of T-regulatory populations. Ultimately, this aberrant inflammation and impaired healing would lead to epithelia destruction, airway cicatrization, pulmonary fibrosis, and air trapping.

\section{Diagnostic Criteria for Bronchiolitis Obliterans Syndrome}

The diagnosis of bronchiolitis obliterans syndrome remains a significant challenge. While transbronchial biopsy is often performed, this test is hindered by low sensitivity (17\%) and poor predictive value. ${ }^{34}$ Lung biopsy remains the criterion standard (FIGURE 2), demonstrating damage to the bronchiolar epithelium, obliteration of bronchiolar lumens, inflammation between the epithelium and smooth muscle, and pulmonary fibrosis. However, lung biopsy may result in severe complications in up to $13 \%$ of patients with chronic graftvs-host disease and bronchiolitis obliterans syndrome, ${ }^{35}$ leading to pneumothoraces, persistent airleak syndrome, pneumomediastinum, or even death. ${ }^{35-38}$ Thus, noninvasive sensitive and specific methods would be the preferred diagnostic approach.

Pulmonary function testing is crucial to diagnose bronchiolitis obliterans syndrome. This syndrome rarely develops in the absence of a new fixedobstructive defect. However, the degree of obstruction diagnostic for bronchiolitis obliterans syndrome is not established for HSCT. Review of the literature reveals 10 distinct definitions of bronchiolitis obliterans syndrome after HSCT. ${ }^{5,9,12,20,39-43}$ The recent NIH consensus definition on bronchiolitis obliterans syndrome provided the benchmark for establishing a standardized definition for this disease. ${ }^{5}$ This definition included parameters to detect the hallmark findings of decreased airflow and air trapping, using pulmonary function tests (FIGURE 3) and CT scans. The NIH definition requires (1) absence of active infection, (2) decreased $\mathrm{FEV}_{1}$ ( $<75 \%$ of predicted normal), (3) evidence of airway obstruction with a ratio of $\mathrm{FEV}_{1}$ to forced vital capacity of less than 0.7 , (4) elevated residual volume of air (>120\% of predicted normal), or (5) an expiratory chest CT or lung biopsy that reveals air trapping (expiration) or bronchiectasis (FIGURE 4). ${ }^{5}$ If a lung biopsy is not performed, another manifestation of chronic graftvs-host disease is needed. ${ }^{5}$

Because of the similar presentation of bronchiolitis obliterans syndrome after lung transplantation and HSCT and the established diagnostic criteria for the former, one might consider the applicability of the lung transplant diagnostic criteria for bronchiolitis obliterans syndrome after HSCT. Candidates for lung transplantation have prior lung disease and abnormal lung function following transplantation. In contrast, most patients who undergo HSCT should have normal lung function before and after the transplantation. ${ }^{44}$ Thus, recipients of HSCT may require alternative monitoring intervals and different thresholds for significant decline in lung function. In addition, recipients of HSCT have conditions that may influence the rate of decline of lung function, including respiratory tract infections, prior exposure to chemotherapy and radiotherapy, and extrinsic factors of steroid myopathies or sclerotic chronic graftvs-host disease (a skin manifestation of chronic graftvs-host disease mimicking scleroderma with or without lung disease). These differences 
have significant implications for the interpretation of pulmonary function tests and the diagnosis of bronchiolitis obliterans syndrome.

Bronchiolitis obliterans syndrome after HSCT and lung transplantation results in decline in $\mathrm{FEV}_{1}$. Following lung transplantation, data suggest that a decline in $\mathrm{FEV}_{1}$ of $10 \%$ to $15 \%$ of predicted normal and a decline in predicted forced midexpiratory flow rate to less than $70 \%$ identify patients with bronchiolitis obliterans syndrome. ${ }^{23}$ After HSCT, decline in lung function from baseline (value prior to the HSCT) is commonly due to lung toxic effects from cytoreductive agents ${ }^{45}$ and infections, decreasing the specificity of these isolated values, especially with regard to the predicted forced midexpiratory flow rate. ${ }^{46}$ Because patients are likely to experience decline in $\mathrm{FEV}_{1}$ after a HSCT (due to other factors distinct from lung transplantation), it is important to establish obstruction in these patients, distinguishing bronchiolitis obliterans syndrome from other causes of $\mathrm{FEV}_{1}$ decline.

The evidence for obstruction by decreased ratio of $\mathrm{FEV}_{1}$ to forced vital capacity is prevalent in patients with bronchiolitis obliterans syndrome after both HSCT and lung transplantation. However, slow vital capacity should be considered in the evaluation of patients with bronchiolitis obliterans syndrome after HSCT. Among patients with dynamic airway obstruction (collapse of airways during forced expiratory maneuver due to increase in intrathoracic pressures from air trapping), the forced vital capacity may underestimate the vital capacity, falsely elevating the ratio of FEV1 to forced vital capacity. Given the current American Thoracic Society guidelines to use the ratio of $\mathrm{FEV}_{1}$ to the highest vital capacity, 47 the published data that patients with bronchiolitis obliterans syndrome may have a decline in forced vital capacity compared with slow vital capacity, ${ }^{48}$ and the evidence for use of the vital capacity in patients with chronic obstructive pulmonary disease, ${ }^{49}$ the highest vital capacity value may be the best marker to identify patients with bronchiolitis obliterans syndrome after HSCT.

Unfortunately, severe restrictive disease in patients with bronchiolitis obliterans syndrome after HSCT may lead to a false normalization of the ratio consistent with a combined disorder of obstruction and restriction (Figure 3A). ${ }^{43}$ Vogelsang et al proposed that sclerotic graft-vs-host disease could mimic restrictive lung disease on pulmonary function tests. ${ }^{50}$ The consensus guidelines ${ }^{5}$ included evidence for air trapping in the diagnostic criteria to aid in the specificity of diagnosis. Elevated residual volume may reveal air trapping by pulmonary function tests, although it is limited by the fact that this parameter is influenced by the estimated total lung capacity and not directly measured. It has been proposed that the ratio of residual volume to total lung capacity be considered for identification of air trapping by pulmonary function tests, ${ }^{51}$ and while this has yet to be tested in the population with bronchiolitis obliterans syndrome, the ratio of residual volume to total lung capacity has been shown to be elevated in patients with scleroderma and obstructive lung disease. ${ }^{52}$ Air trapping also is denoted by a mosaic pattern on CT scans. While this test is limited to subjective interpretation, which limits sensitivity, ${ }^{52-56}$ a recent study has substantiated that this was the most specific imaging finding for bronchiolitis obliterans syndrome. ${ }^{57}$

To place these diagnostic criteria for bronchiolitis obliterans syndrome after HSCT in context, the consensus definition ${ }^{5}$ was recently applied at the NIH to a series of patients with 
clinically identified $(n=15)$ or biopsy-proven $(n=7)$ bronchiolitis obliterans syndrome. Only $18 \%$ (4/22) of patients met the NIH consensus definition for a clinical diagnosis of bronchiolitis obliterans and all of these patients had an $\mathrm{FEV}_{1}$ of $55 \%$ of predicted normal or less, which is suggestive of severe disease. Most patients had a decreased ratio of $\mathrm{FEV}_{1}$ to forced vital capacity of less than 0.7 or a ratio of $\mathrm{FEV}_{1}$ to slow vital capacity of less than 0.7 , which are indicative of airflow obstruction and consistent with definitions of lung transplantation bronchiolitis obliterans syndrome. Most of the remainder did have air trapping by expiratory $\mathrm{CT}$ and residual volume or a ratio of residual volume to total lung capacity of greater than $120 \%$ of predicted. Interestingly, these latter patients had sclerotic graft-vs-host disease or graft-vshost disease myositis, corroborating prior suggestions that these chronic graft-vs-host disease manifestations could mask the ratio of $\mathrm{FEV}_{1}$ to forced vital capacity. ${ }^{50}$

Studies are needed to compare clinical parameters of biopsy-proven bronchiolitis obliterans syndrome with biopsy-proven non-bronchiolitis obliterans syndrome to evaluate the sensitivity and specificity of these definitions. However, because therapeutic trials in this disease are currently in development and under way, these summaries of the literature may provide a catalyst to initiate protocols with less stringent definitions for bronchiolitis obliterans syndrome with nontoxic agents, reserving stringent diagnostic criteria for more toxic agents.

Finally, $\mathrm{FEV}_{1}$ decline over time may present the greatest opportunity for an earlier, more sensitive and specific diagnosis of bronchiolitis obliterans syndrome (Figure 1). ${ }^{9}$ An approach already adopted by the lung transplantation community is the use of the magnitude of $\mathrm{FEV}_{1}$ decline from pretransplant values, which maybe better for the diagnosis of bronchiolitis obliterans syndrome than a strict $\mathrm{FEV}_{1}$ threshold. ${ }^{58}$ If a patient receives a HSCT with an $\mathrm{FEV}_{1}$ of $110 \%$ of predicted normal, an unexplained irreversible decline exceeding $10 \%$ over a short period (eg, 1 year) should prompt an evaluation. Alternatively, a patient with an $\mathrm{FEV}_{1}$ of $75 \%$ of predicted normal and mild obstruction prior to HSCT, who experiences a mild decline of only a few percentage points, should not be sufficient for diagnosis of bronchiolitis obliterans syndrome. Close monitoring of pulmonary function tests after the transplantation could thus improve diagnosis. A decline in $\mathrm{FEV}_{1}$ of greater than $5 \%$ per year with a ratio of $\mathrm{FEV}_{1}$ to forced vital capacity of less than 0.8 has been shown to identify air flow obstruction after transplantation. ${ }^{18}$

Airflow obstruction, a likely precursor of bronchiolitis obliterans, conferred a significantly increased risk in mortality of 2.3 -fold (95\% confidence interval, 1.6- to 3.3-fold; $P<.001$ ) above patients without airflow obstruction, with a significant increase in attributable mortality in patients with chronic graft-vs-host disease. While not all of these patients have bronchiolitis obliterans syndrome (eg, some will have infection), this study suggests that monitoring pulmonary function in patients at risk for the development of bronchiolitis obliterans syndrome with frequent pulmonary function tests or spirometry after transplantation (every 3 months) may enable a diagnosis of airflow obstruction, thus aiding in early identification of patients at risk for subsequent death from bronchiolitis obliterans syndrome. ${ }^{18}$ Consideration of the costs and potential benefits of this monitoring should be 
addressed in future clinical studies, which are necessary to identify the HSCT patient population and the target timeframe for lung function surveillance.

Treatment

Studies suggest that less than $20 \%$ of patients improve and $65 \%$ of patients with bronchiolitis obliterans syndrome and chronic graft-vs-host disease will die within 3 years of the diagnosis of bronchiolitis obliterans syndrome regardless of the therapies instituted. $8,18,42$ In these studies, standard treatments included immunosuppressive agents such as corticosteroids, cyclosporine, azathioprine, and antithymocyte globulin. For patients not responding to the initial course of immunosuppressive treatment, the 2-year and 5-year survival rates were $20 \%$ and $13 \%$, respectively. ${ }^{9}$ Recommended therapy includes high-dose systemic corticosteroids $(1 \mathrm{mg} / \mathrm{kg} / \mathrm{d})$ for a protracted course with expected improvements in $8 \%$ to $20 \%$ of patients, of which few are likely durable given the poor overall survival., ${ }^{9,59-61}$ The addition of other immunosuppressants (eg, calcineurin inhibitors, sirolimus) seems logical and may be beneficial although this has not been tested in trials of HSCT recipients.

In lung transplantation, this concept has been demonstrated; T-cell immunosuppressive agents such as tacrolimus and antithymocyte globulin have delayed progression of bronchiolitis obliterans syndrome after lung transplantation. ${ }^{62,63}$ There are some data for regular use of azithromycin, which has anti-inflammatory as well as antiinfectious properties, to treat bronchiolitis obliterans syndrome after lung transplantation. ${ }^{24,64-69}$ However, these studies are small and inconsistent. ${ }^{70,71}$ Anecdotal evidence has accumulated for extracorporeal photopheresis (6/7 patients with stable disease) and tumor necrosis factor blockade (1/1 patient with stable disease). ${ }^{59,72-74}$ A retrospective study also suggested that statins, which can exhibit anti-inflammatory properties, may decrease the incidence of bronchiolitis obliterans syndrome after lung transplantation. ${ }^{75}$ From studies of murine and human bronchoalveolar lavage, leukotriene inhibitors have emerged as a potential therapy. Elevated levels of leukotrienes have been implicated in bronchiolitis obliterans syndrome after lung transplantation and pulmonary fibrosis in human and murine studies. ${ }^{76-78}$ Published data reveal that 3 of 5 patients with bronchiolitis obliterans syndrome had improvements with montelukast, an agent that inhibits leukotriene activity. ${ }^{79}$ Collectively, these agents represent candidate treatments that need to be evaluated rigorously in clinical trials.

A NIH phase 2 trial is ongoing to test the efficacy of montelukast for the treatment of bronchiolitis obliterans syndrome. With improved understanding of the pathogenesis of this disease, it may be possible to identify the atrisk recipients of HSCT and to ameliorate early disease.

\section{CONCLUSION}

In the case presented, the patient underwent 2 open lung biopsies that demonstrated bronchiolitis obliterans syndrome after HSCT. While the first biopsy did provide additional infection information, the second investigation could potentially be avoided with improved diagnostic criteria. The patient is currently stable and is receiving extracorporeal photopheresis and montelukast therapy several years later. 
As patients live longer following HSCT, the incidence of complications from chronic graftvs-host disease and bronchiolitis obliterans syndrome is likely to increase. A better understanding of disease diagnosis and pathogenesis will be critical to altering survival statistics in this highly fatal disease.

Furthermore, monitoring of pulmonary function early after transplantation maybe warranted. This patient lost $50 \%$ of her lung function prior to the first pulmonary function test at 1 year posttransplantation even though she had several risk factors for bronchiolitis obliterans syndrome, including HLA mismatch, acute graft-vs-host disease, and cytomegalovirus positivity. The chronic graft-vs-host disease academic community recommends consideration of the pulmonary function test or spirometry every 3 months during the first year after transplantation in high-risk patients and infectious and radiographic investigation for any persistent decline (either a decline of $>10 \%$ for the percentage of predicted $\mathrm{FEV}_{1}$ or a decline of $>5 \%$ per year for $\left.\mathrm{FEV}_{1}\right){ }^{80}$

Future studies need to focus on elucidating the mechanisms underlying the genesis of bronchiolitis obliterans syndrome after HSCT. With better understanding of inflammatory antigens, pathogenic cytokines, and destructive cellular populations, new treatments that target these pathways may be selected. Currently, the therapies for bronchiolitis obliterans syndrome after transplantation involve severe immunosuppression, which may result in serious infectious complications.

Reduction of mortality rates will require improved tolerance, enhanced immune surveillance for infections, and optimal lung epithelial healing. Participation in clinical trials that test new therapeutics and generate new investigations into pathogenesis of disease will be critical. Finally, it is likely that early identification of bronchiolitis obliterans syndrome will be essential to alter the course of this disease's natural history.

\section{Acknowledgments}

Funding/Support: This project was supported in part by the National Cancer Institute, National Institutes of Health, Intramural Research Program, Center for Cancer Research. Dr Chien is supported by research grant HL088201 from the National Institutes of Health.

Role of the Sponsor: The National Institutes of Health had a role in the design and conduct of the study; collection, management, analysis, and interpretation of the data, or in the preparation, review, or approval of the manuscript.

\section{REFERENCES}

1. Copelan EA. Hematopoietic stem-cell transplantation. N Engl J Med. 2006;354(17):18131826. [PubMed: 16641398]

2. Bhushan V, Collins RH Jr. Chronic graft-vs-host disease. JAMA. 2003;290(19):2599-2603. [PubMed: 14625337]

3. Stewart BL, Storer B, Storek Jr. et al. Duration of immunosuppressive treatment for chronic graftversushost disease. Blood. 2004;104(12)3501-3506. [PubMed: 15292060]

4. Lee SJ, Flowers ME. Recognizing and managing chronic graft-versus-host disease. Hematology Am Soc Hematol Educ Program. 2008;2008:134141.

5. Filipovich AH, Weisdorf D, Pavletic S, et al. National Institutes of Health consensus development project on criteria for clinical trials in chronic graftversus-host disease, I: diagnosis and staging working group report. Biol Blood Marrow Transplant. 2005; 11(12):945-956. [PubMed: 16338616] 
6. Pavletic SZ, Martin P, Lee SJ, et al.; Response Criteria Working Group. Measuring therapeutic response in chronic graft-versus-host disease: National Institutes of Health Consensus Development Project on Criteria for Clinical Trials in Chronic Graft-versusHost Disease, IV: Response Criteria Working Group report. Biol Blood Marrow Transplant. 2006;12 (3):252-266. [PubMed: 16503494]

7. Martin PJ, Weisdorf D, Przepiorka D, et al.; Design of Clinical Trials Working Group. National Institutes of Health Consensus Development Project on Criteria for Clinical Trials in Chronic Graftvers us-Host Disease, VI: Design of Clinical Trials Working Group report. Biol Blood Marrow Transplant. 2006; 12 (5):491-505. [PubMed: 16635784]

8. Clark JG. The challenge of bone marrow transplantation. Mayo Clin Proc. 1990;65(1):111114. [PubMed: 2296204]

9. Dudek AZ, Mahaseth H, DeFor TE, Weisdorf DJ. Bronchiolitis obliterans in chronic graft-versushost disease: analysis of risk factors and treatment outcomes. Biol Blood Marrow Transplant. 2003;9(10): 657666. [PubMed: 14569562]

10. Nicod LP. Mechanisms of airway obliteration after lung transplantation. Proc Am Thorac Soc. 2006; 3(5):444-449. [PubMed: 16799090]

11. Belperio JA, Lake K, Tazelaar H, Keane MP, Strieter RM, Lynch JP III. Bronchiolitis obliterans syndrome complicating lung or heart-lung transplantation. Semin Respir Crit Care Med. 2003;24(5):499-530. [PubMed: 16088570]

12. Clark JG, Crawford SW, Madtes DK, Sullivan KM. Obstructive lung disease after allogeneic marrow transplantation: clinical presentation and course. Ann Intern Med. 1989;111 (5):368-376. [PubMed: 2669592]

13. Santo Tomas LH, Loberiza FR Jr, Klein JP, et al. Risk factors for bronchiolitis obliterans in allogeneic hematopoietic stem-cell transplantation for leukemia. Chest. 2005;128(1 ):153-161. [PubMed: 16002929]

14. Marras TK, Chan CK, Lipton JH, Messner HA, Szalai JP, Laupacis A. Long-term pulmonary function abnormalities and survival after allogeneic marrow transplantation. Bone Marrow Transplant. 2004;33(5):509-517. [PubMed: 14716347]

15. Holland HK, Wingard JR, Beschorner WE, Saral R, Santos GW. Bronchiolitis obliterans in bone marrow transplantation and its relationship to chronic graftv-host disease and low serum IgG. Blood. 1988; 72(2):621-627. [PubMed: 3042044]

16. Clark JG, Schwartz DA, Flournoy N, Sullivan KM, Crawford SW, Thomas ED. Risk factors for airflow obstruction in recipients of bone marrow transplants. Ann Intern Med. 1987; 107(5):648656. [PubMed: 3310793]

17. Afessa B, Litzow MR, Tefferi A. Bronchiolitis obliterans and other late onset non-infectious pulmonary complications in hematopoietic stem cell transplantation. Bone Marrow Transplant. 2001; 28(5):425-434. [PubMed: 11593314]

18. Chien JW, Martin PJ, Gooley TA, et al. Airflow obstruction after myeloablative allogeneic hematopoietic stem cell transplantation. Am J Respir Crit Care Med. 2003;168(2):208-214. [PubMed: 12649126]

19. Yousem SA. The histological spectrum of pulmonary graft-versus-host disease in bone marrow transplant recipients. Hum Pathol. 1995;26(6):668675. [PubMed: 7774899]

20. Philit F, Wiesendanger T, Archimbaud E, Mornex JF, Brune J, Cordier JF. Post-transplant obstructive lung disease ("bronchiolitis obliterans"): a clinical comparative study of bone marrow and lung transplant patients. Eur Respir J. 1995;8(4):551-558. [PubMed: 7664853]

21. de Jong PA, Dodd JD, Coxson HO, et al. Bronchiolitis obliterans following lung transplantation: early detection using CT. Thorax. 2006;(5):2.

22. Schulman LL, Weinberg AD, McGregor CC, Suciu-Foca NM, Itescu S. Influence of donor and recipient HLA locus mismatching on development of obliterative bronchiolitis after lung transplantation. Am J Respir Crit Care Med. 2001; 163(2):437-442. [PubMed: 11179119]

23. Reynaud-Gaubert M, Thomas P, Badier M, Cau P, Giudicelli R, Fuentes P. Early detection of airway involvement in obliterative bronchiolitis after lung transplantation: functional and bronchoalveolar lavage cell findings. Am J Respir Crit Care Med. 2000;161 (6): 1924-1929. [PubMed: 10852768] 
24. Verleden GM, Vanaudenaerde BM, Dupont LJ, Van Raemdonck DE. Azithromycin reduces airway neutrophilia and interleukin-8 in patients with bronchiolitis obliterans syndrome. Am J Respir Crit Care Med. 2006;174(5):566-570. [PubMed: 16741151]

25. Duncan SR, Leonard C, Theodore J, et al. Oligoclonal CD4(+) T cell expansions in lung transplant recipients with obliterative bronchiolitis. Am J Respir Crit Care Med. 2002;165(10):1439-1444. [PubMed: 12016109]

26. Jaramillo A, Smith MA, Phelan D, et al. Temporal relationship between the development of antiHLA antibodies and the development of bronchiolitisN obliterans syndrome after lung transplantation. Transplant Proc. 1999;31(1-2):185-186. [PubMed: 10083069]

27. Fukami N, Ramachandran S, Saini D, et al. Antibodies to AAHC class I induce autoimmunity: role in the pathogenesis of chronic rejection. J Immunol. 2009; 182(1):309-318. [PubMed: 19109162]

28. Vanaudenaerde BM, De Vleeschauwer SI, Vos R, et al. The role of the IL23/IL17 axis in bronchiolitis obliterans syndrome after lung transplantation. Am J Transplant. 2008;8(9):19111920. [PubMed: 18786233]

29. BurlinghamWJ LoveRB,Jankowska-Gan E,et al. IL-17-dependent cellular immunity to collagen type $\mathrm{V}$ predisposes to obliterative bronchiolitis in human lung transplants. J Clin Invest. 2007;117(11)34983506. [PubMed: 17965778]

30. Vanaudenaerde BM, Wuyts WA, Geudens N, et al. Macrolides inhibit IL17-induced IL8 and 8isoprostane release from human airway smooth muscle cells. Am J Transplant. 2007;7(1):76-82. [PubMed: 17061983]

31. Botturi K, Lacoeuille Y, Thomas P, Boniface S, Reynaud-Gaubert M, Magnan A. CTLA-4mediated regulatory phenotype of T-cells in tolerant lung recipients. Eur Respir J. 2008;31 (6):1167-1176. [PubMed: 18256061]

32. Mamessier E, Lorec AM, Thomas P, Badier M, Magnan A, Reynaud-Gaubert M. T regulatory cells in stable posttransplant bronchiolitis obliterans syndrome. Transplantation. 2007;84(7):908-916. [PubMed: 17984845]

33. Bharat A, Fields RC, Steward N, Trulock EP, Patterson GA, Mohanakumar T. CD4+25+ regulatory T cells limit Th1-autoimmunity by inducing IL-10 producingT cells following human lung transplantation. Am J Transplant. 2006;6(8):1799-1808. [PubMed: 16889540]

34. Chamberlain DA, Maurer J, Chaparro C, Idolor L. Evaluation of transbronchial lung biopsy specimens in the diagnosis of bronchiolitis obliterans after lung transplantation. J Heart Lung Transplant. 1994; 13(6):963-971. [PubMed: 7865530]

35. White DA, Wong PW, Downey R. The utility of open lung biopsy in patients with hematologic malignancies. Am J Respir Crit Care Med. 2000; 161(3 pt1):723-729. [PubMed: 10712314]

36. Suzuki T, Saijo Y, Ebina M, et al. Bilateral pneumothoraces with multiple bullae in a patient with asymptomatic bronchiolitis obliterans 10 years after bone marrow transplantation. Bone Marrow Transplant. 1999;23(8):829-831. [PubMed: 10231147]

37. Chadwick C, Marven SM, Vora AJ. Autologous blood pleurodesis for pneumothorax complicating graft-versus-host disease-related bronchiolitis obliterans. Bone Marrow Transplant. 2004;33(4): 451-453. [PubMed: 14716352]

38. Kumar S, Tefferi A. Spontaneous pneumomediastinum and subcutaneous emphysema complicating bronchiolitis obliterans after allogeneic bone marrow transplantation-case report and review of literature. Ann Hematol. 2001;80(7):430-435. [PubMed: 11529471]

39. Yoshihara S, Yanik G, Cooke KR, Mineishi S. Bronchiolitis obliterans syndrome (BOS), bronchiolitis obliterans organizing pneumonia (BOOP), and other lateonset noninfectious pulmonary complications following allogeneic hematopoietic stem cell transplantation. Biol Blood Marrow Transplant. 2007;13(7):749-759. [PubMed: 17580252]

40. Curtis DJ, Smale A, Thien F, Schwarer AP, Szer J. Chronic airflow obstruction in long-term survivors of allogeneic bone marrow transplantation. Bone Marrow Transplant. 1995;16(1): 169173. [PubMed: 7581118]

41. Markopoulo KD, Cool CD, ElliotTL, et al. Obliterative bronchiolitis: varying presentations and clinicopathological correlation. Eur Respir J. 2002;19 (1):20-30. [PubMed: 11843321] 
42. Chan CK, Hyland RH, Hutcheon MA, et al. Smallairways disease in recipients of allogeneic bone marrow transplants: an analysis of 11 cases and a review of the literature. Medicine (Baltimore). 1987;66 (5)327-340. [PubMed: 3306259]

43. Yokoi T, Hirabayashi N, Ito M, et al.; NagoyaBMT Group. Broncho-bronchiolitis obliterans as a complication of bone marrow transplantation: aclinicopatho-n logical study of eight autopsy cases. Virchows Arch. 1997;431 (4):275-282. [PubMed: 9368665]

44. Parimon T, Madtes DK, Au DH, Clark JG, Chien JW. Pretransplant lung function, respiratoryfailure, and mortality after stem cell transplantation. Am J Respir Crit Care Med. 2005;172(3)384-390. [PubMed: 15894602]

45. Sutedja TG, Apperley JF, Hughes JM, et al. Pulmonary function after bone marrow transplantation for chronic myeloid leukaemia. Thorax. 1988;43 (3):163-169. [PubMed: 3043753]

46. Hansen JE, Sun XG, Wasserman K. Discriminating measures and normal values for expiratory obstruction. Chest. 2006;129(2)369-377. [PubMed: 16478854]

47. Pellegrino R, Viegi G, Brusasco V, et al. Interpretative strategies for lung function tests. Eur Respir J. 2005;26(5):948-968. [PubMed: 16264058]

48. Cohen J, Postma DS, Vink-Klooster K, et al. FVC to slow inspiratory vital capacity ratio: a potential marker for small airways obstruction. Chest. 2007; 132(4): 1198-1203. [PubMed: 17890480]

49. Nathell L, Nathell M, Malmberg P, Larsson K. COPD diagnosis related to different guidelines and spirometry techniques. Respir Res. 2007;8:89. [PubMed: 18053200]

50. Vogelsang GB, Lee L, Bensen-Kennedy DM. Pathogenesis and treatment of graft-versus-host disease after bone marrow transplant. Annu Rev Med. 2003; 54:29-52. [PubMed: 12359826]

51. Diez Herranz A. RV/TLC\% ratio: alternative criteria of normality. Eur Respir J. 1995;8(10):18121813. [PubMed: 8586145]

52. Guttadauria M, Ellman H, Emmanuel G, Kaplan D, Diamond H. Pulmonary function in scleroderma. Arthritis Rheum. 1977;20(5):1071-1079. [PubMed: 869954]

53. Miller WT Jr, Kotloff RM, Blumenthal NP, Aronchick JM, Gefter WB, Miller WT. Utility of high resolution computed tomography in predicting bronchiolitis obliterans syndrome following lung transplantation: preliminary findings. J Thorac Imaging. 2001; 16(2):76-80. [PubMed: 11292208]

54. Choi YW, Rossi SE, Palmer SM, DeLong D, Erasmus JJ, McAdams HP. Bronchiolitis obliterans syndrome in lung transplant recipients: correlation of computed tomography findings with bronchiolitis obliterans syndrome stage. J Thorac Imaging. 2003; 18(2):7279. [PubMed: 12700480]

55. Bankier AA, Van Muylem A, Knoop C, Estenne M, Gevenois PA. Bronchiolitis obliterans syndrome in heart-lung transplant recipients: diagnosis with expiratory CT. Radiology. 2001;218(2):533-539. [PubMed: 11161175]

56. Leung AN, Fisher K, Valentine V, et al. Bronchiolitis obliterans after lung transplantation: detection using expiratory HRCT. Chest. 1998;113(2)365370. [PubMed: 9498953]

57. Gunn ML, Godwin JD, Kanne JP, Flowers ME, Chien JW. High-resolution CT findings of bronchiolitis obliterans syndrome after hematopoietic stem cell transplantation. J Thorac Imaging. 2008;23(4): 244-250. [PubMed: 19204468]

58. Estenne M, Maurer JR, Boehler A, et al. Bronchiolitis obliterans syndrome 2001: an update of the diagnostic criteria. J Heart Lung Transplant. 2002; 21(3):297-310. [PubMed: 11897517]

59. Fullmer JJ, Fan LL, Dishop MK, Rodgers C, Krance R. Successful treatment of bronchiolitis obliterans in a bone marrow transplant patient with tumor necrosis factor-alpha blockade. Pediatrics. 2005;116 (3): 767-770. [PubMed: 16140721]

60. Ratjen F, Rjabko O, Kremens B. High-dose corticosteroid therapy for bronchiolitis obliterans after bone marrow transplantation in children. Bone Marrow Transplant. 2005;36(2):135-138. [PubMed: 15908967]

61. Duncan CN, Buonanno MR, Barry EV, Myers K, Peritz D, Lehmann L. Bronchiolitis obliterans following pediatric allogeneic hematopoietic stem cell transplantation. Bone Marrow Transplant. 2008; 41(11):971-975. [PubMed: 18297116] 
62. Hollmén M, Tikkanen JM, Nykanen AI, Koskinen PK, Lemstrom KB. Tacrolimus treatment effectively inhibits progression of obliterative airway disease even at later stages of disease development. J Heart Lung Transplant. 2008;27(8):856-864. [PubMed: 18656798]

63. Snell GI, Esmore D\$, Williams TJ. Cytolytic therapy for the bronchiolitis obliterans syndrome complicating lung transplantation. Chest. 1996;109(4): 874-878. [PubMed: 8635363]

64. Gottlieb J, Szangolies J, Koehnlein T, Golpon H, Simon A, Welte T. Long-term azithromycin for bronchiolitis obliterans syndrome after lung transplantation. Transplantation. 2008;85(1):36-41. [PubMed: 18192909]

65. Verleden GM, Dupont LJ. Azithromycin therapy for patients with bronchiolitis obliterans syndrome after lung transplantation. Transplantation. 2004; 77(9):1465-1467. [PubMed: 15167610]

66. Gerhardt SG, McDyer JF, Girgis RE, Conte JV, Yang SC, Orens JB. Maintenance azithromycin therapy for bronchiolitis obliterans syndrome: results of a pilot study. Am J Respir Crit Care Med. 2003; 168(1): 121-125. [PubMed: 12672648]

67. Khalid M, Al Saghir A, Saleemi S, et al. Azithromycin in bronchiolitis obliterans complicating bone marrow transplantation: a preliminary study. Eur Respir J. 2005;25(3):490-493. [PubMed: 15738293]

68. Yates B, Murphy DM, Forrest IA, et al. Azithromycin reverses airflow obstruction in established bronchiolitis obliterans syndrome. Am J Respir Crit Care Med. 2005;172(6):772-775. [PubMed: 15976371]

69. Verleden GM, Dupont LJ, Vanhaecke J, Daenen W, Van Raemdonck DE. Effect of azithromycin on bronchiectasis and pulmonary function in a heart-lung transplant patient with severe chronic allograft dysfunction: a case report. J Heart Lung Transplant. 2005; 24(8):1155-1158. [PubMed: 16102464]

70. Porhownik NR, Batobara W, Kepron W, Unruh HW, Bshouty Z, Effect of maintenance azithromycin on established bronchiolitis obliterans syndrome in lung transplant patients. Can Respir J. 2008; 15(4): 199202. [PubMed: 18551201]

71. Shitrit D, Bendayan D, Gidon S, Saute M, Bakal I, Kramer MR. Long-term azithromycin use for treatment of bronchiolitis obliterans syndrome in lung transplant recipients. J Heart Lung Transplant. 2005; 24(9):1440-1443. [PubMed: 16143268]

72. Smith EP, Sniecinski I, Dagis AC, et al. Extracorporeal photochemotherapy for treatment of drugresistant graft-vs-host disease. Biol Blood Marrow Transplant. 1998;4(1):27-37. [PubMed: 9701389]

73. Besnier DP, Chabannes D, Mahe B, et al. Treatment of graft-versus-host disease by extracorporeal photochemotherapy: a pilot study. Transplantation. 1997;64(1):49-54. [PubMed: 9233700]

74. Ilhan O, Arat M, Arslan O, et al. Extracorporeal photoimmunotherapy for the treatment of steroid refractory progressive chronic graft-versus-host disease. Transfus Apheresis Sci. 2004;30(3):185187.

75. Johnson BA, lacono AT, Zeevi A, McCurry KR, Duncan SR. Statin use is associated with improved function and survival of lung allografts. Am J Respir Crit Care Med. 2003;167(9):1271-1278. [PubMed: 12615629]

76. Islam SA, Thomas SY, Hess C, et al. The leukotriene B4 lipid chemoattractant receptor BLT1 defines antigen-primed T cells in humans. Blood. 2006; 107(2):444-453. [PubMed: 16179368]

77. Wilborn J, Bailie M, Coffey M, Burdick M, Strieter R, Peters-Golden M. Constitutive activation of 5-lipoxygenase in the lungs of patients with idiopathic pulmonary fibrosis. J Clin Invest. 1996;97 (8):1827-1836. [PubMed: 8621765]

78. Medoff BD, Seung E, Wain JC, et al. BLT1mediated T cell trafficking is critical for rejection and obliterative bronchiolitis after lung transplantation. J Exp Med. 2005;202(1):97-110. [PubMed: 15998790]

79. Or R, Gesundheit B, Resnick I, et al. Sparing effect by montelukast treatment for chronic graft versus host disease: a pilot study. Transplantation. 2007;83 (5):577-581. [PubMed: 17353777]

80. Couriel D, Carpenter PA, Cutler C, et al.; Ancillary Therapy and Supportive Care Working Group Report. Ancillary therapy and supportive care of chronic graft-versus-host disease: national institutes of health consensus development project on criteria for clinical trials in chronic Graft- 
versus-host disease, V: Ancillary Therapy and Supportive Care Working Group report. Biol Blood Marrow Transplant. 2006; 12 (4):375-396. [PubMed: 16545722] 


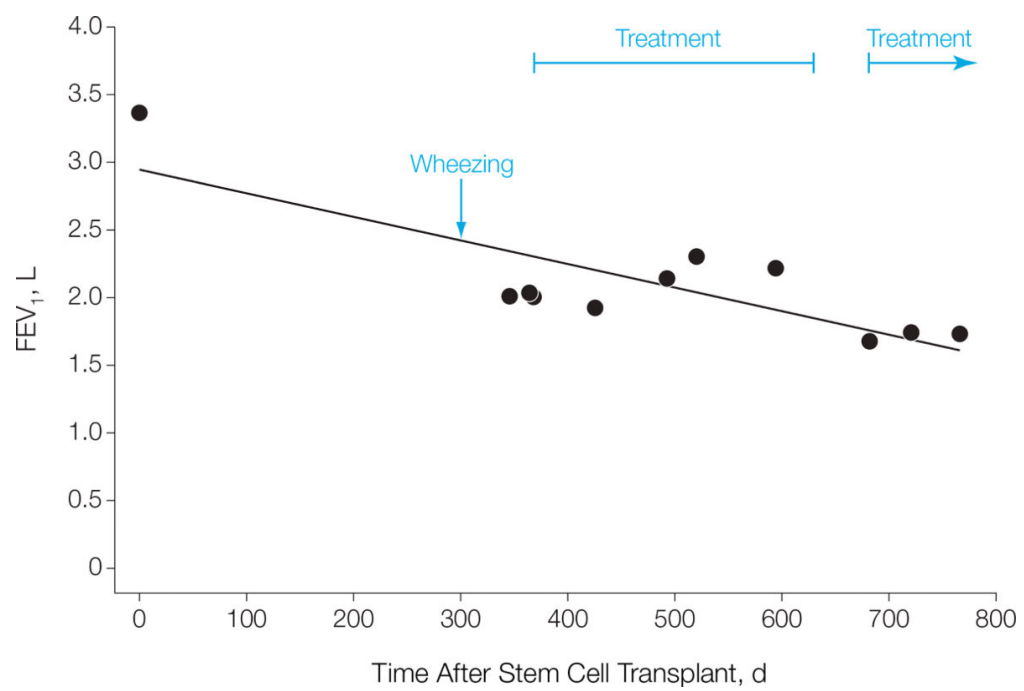

Figure 1. Pulmonary Function Test of FEV 1 Over Time After Hematopoietic Stem Cell Transplantation

$\mathrm{FEV}_{1}$ indicates forced expiratory volume in the first second of expiration. 

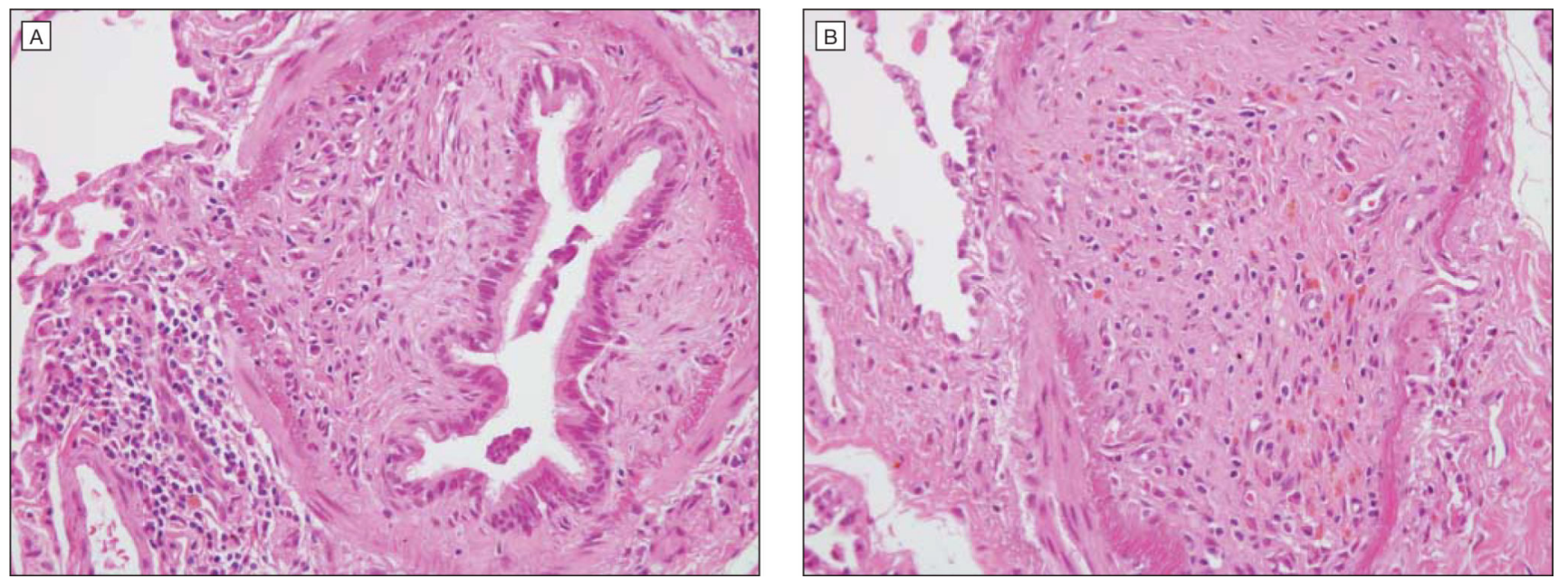

Figure 2. Biopsy of Case Patient's Lung Tissue

A, Obliteration of bronchiolar lumen (hematoxylin-eosin, original magnification $\times 400$ ). B, Inflammation between the epithelium and the smooth muscle (hematoxylin-eosin, original magnification $\times 400$ ). 
A Spirogram

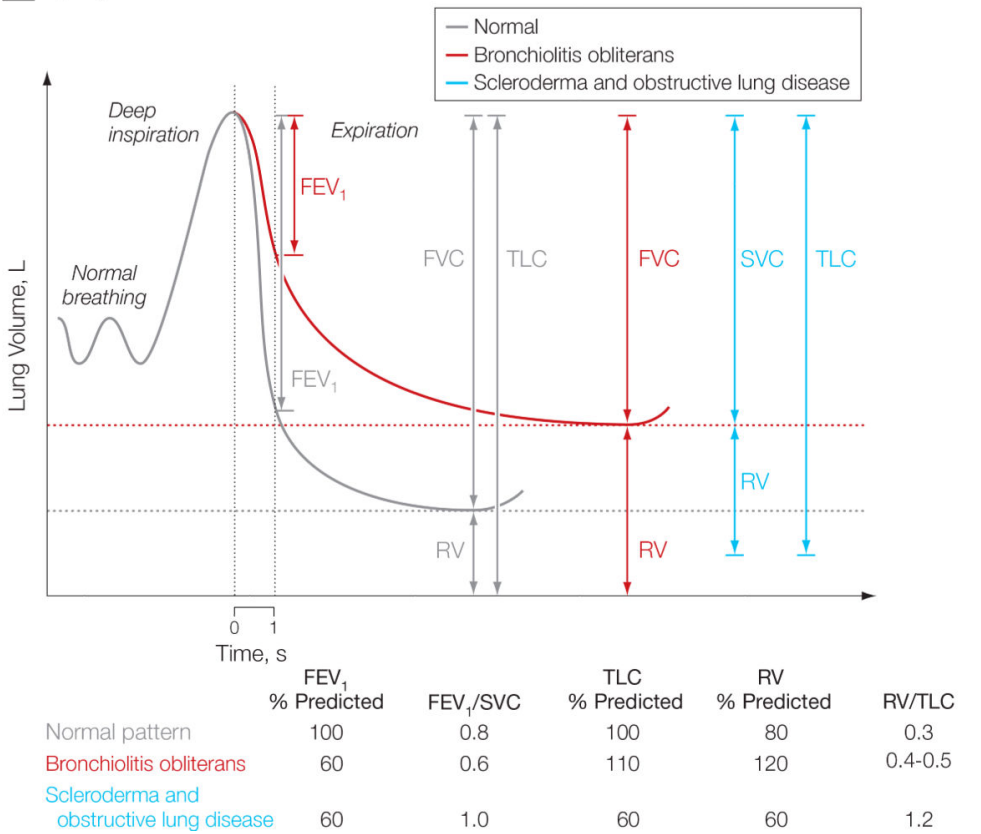

B Flow-volume curve

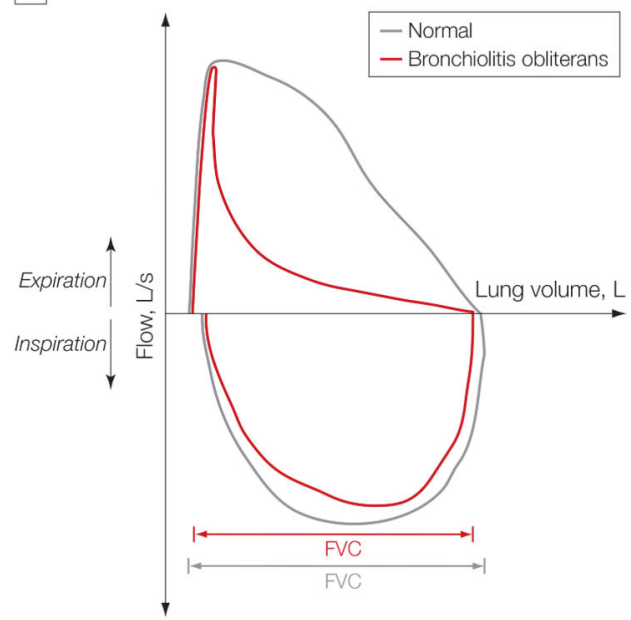

Figure 3. Hypothetical Spirogram and Flow Volume Curves for Bronchiolitis Obliterans Syndrome

The pulmonary function test pattern shown for patients with scleroderma and obstructive lung disease has been observed in patients with sclerotic graft-vs-host disease. $\mathrm{FEV}_{1}$ indicates forced expiratory volume in the first second of expiration; FVC, forced vital capacity; RV, residual volume; SVC, slow vital capacity; TLC, total lung capacity. 
A Case patient $\left(\mathrm{FEV}_{1}, 50 \%\right.$ of predicted normal)

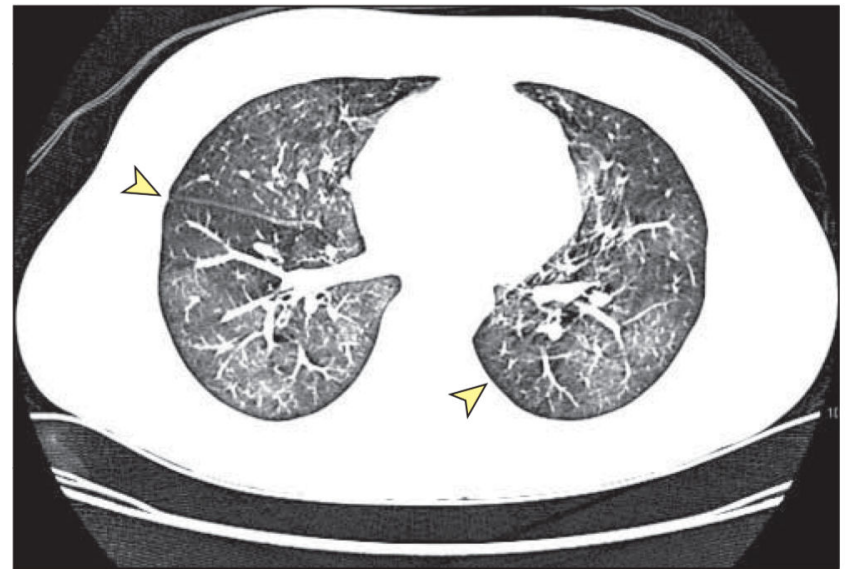

$B$ Example of patient with severe $\mathrm{BO}\left(\mathrm{FEV}_{1}, 24 \%\right.$ of predicted normal)

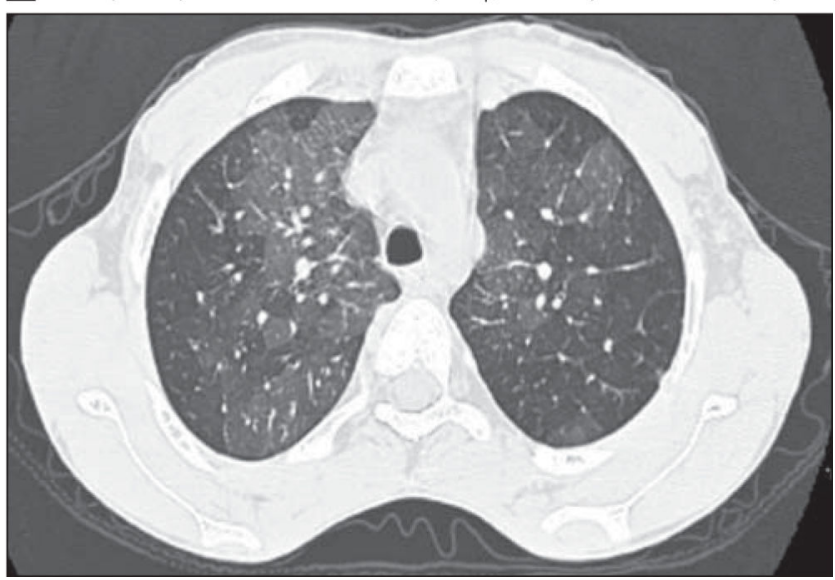

Figure 4. Chest Computed Tomography Scans for Bronchiolitis Obliterans (BO) Syndrome A, Arrowheads indicate areas of air trapping. B, Dark areas show large areas of air trapping. Image contrast in panel $\mathrm{A}$ has been increased to accentuate areas of air trapping. $\mathrm{FEV}_{1}$ indicates forced expiratory volume in the first second of expiration. 